\title{
Removal of methyl violet 2B dye from aqueous solution using Nepenthes rafflesiana pitcher and leaves
}

\author{
Muhammad Raziq Rahimi $\operatorname{Kooh}^{1}$ (D) Muhammad Khairud Dahri ${ }^{1}$ • \\ Linda B. L. Lim ${ }^{1}$
}

Received: 6 December 2016/ Accepted: 24 January 2017/Published online: 6 February 2017

(C) The Author(s) 2017. This article is published with open access at Springerlink.com

\begin{abstract}
This study reported Nepenthes rafflesiana pitcher (NP) and Nepenthes rafflesiana leaves (NL) as new adsorbents for methyl violet (MV) dye. The experiments were done using $2 \mathrm{~h}$ contact time and without any $\mathrm{pH}$ alteration ( $\mathrm{pH}$ 4.4). The effects of $\mathrm{pH}$ and ionic strength revealed hydrophobic-hydrophobic interaction as the predominant force of dye interaction with the adsorbent. Both NP-MV and NL-MV followed pseudo-second-order model indicating the adsorption processes may be governed by chemical process. Weber-Morris intraparticle diffusion model verified that the rate-limiting step of both the NPMV and NL-MV systems is not intraparticle diffusion. The Langmuir model best described the adsorption process with high maximum monolayer adsorption $\left(q_{\mathrm{m}}\right)$ of 288.7 and $194.0 \mathrm{mg} \mathrm{g}^{-1}$ for NP-MV and NL-MV, respectively. Thermodynamics studies revealed both NP-MV and NLMV systems are spontaneous and endothermic in nature. From the regeneration study, it was found that NP's and NL's adsorption capacities could be recovered using distilled water and base whereby distilled water was able to recover $78 \%(\mathrm{NP})$ and $71 \%(\mathrm{NL})$ while base was able to recover $82 \%$ for both samples after three regeneration cycles.
\end{abstract}

Muhammad Raziq Rahimi Kooh

chernyuan@hotmail.com

Muhammad Khairud Dahri

kiddri86@hotmail.com

Linda B. L. Lim

linda.lim@ubd.edu.bn

1 Chemical Sciences Programme, Universiti Brunei Darussalam, Jalan Tungku Link, Pengkalan Gadong, Bandar Seri Begawan BE 1410, Brunei Darussalam
Keywords Nepenthes rafflesiana (Pitcher plant) · Methyl violet $2 \mathrm{~B} \cdot$ Adsorption

\section{Introduction}

The industrialisation and urbanisation of nations sometimes sacrifice the environment for short-term economic gains. Water pollution is a serious concern, and without proper management will lead to irreversible environmental damages. Textile industry is a very water-intensive industry and is ranked as top ten most polluting industry in respect to water pollution (Kant 2012; Rasul et al. 2006). Improper practice of discharging textile wastewater into rivers is still happening, especially in many lower income countries (de Lima et al. 2007; Rasul et al. 2006).

Many dye wastewater methods have been innovated and improved. To name a few remediation methods, there are adsorption, phytoremediation (Kooh et al. 2016a), photocatalyst (Saravanan et al. 2013) and nanoparticles (Agarwal et al. 2016). Adsorption is currently the most popular and most researched method in the last decade (Wang et al. 2011) due to its simplicity in design and can be easily integrated into factory. The cost of wastewater remediation by adsorption depends on the type of adsorbents. To ensure economic feasibility of the wastewater remediation process, one may choose materials that are renewable, sustainable, abundantly available or materials with little values such as agricultural wastes (Gupta and Nayak 2012; Kooh et al. 2016b) and weeds (Lim et al. 2014). Activated carbon may have been ideal materials for certain dyes and heavy metals; however, to produce them may be energy intensive.

This study investigates the pitcher and the leaves of Nepenthes rafflesiana (NR), a species of pitcher plant, as 
potential adsorbents for removal of methyl violet $2 \mathrm{~B}(\mathrm{MV})$ dye. Nepenthes is a carnivorous plant, usually with a juglike leaf which attracts, traps and digests animal to meet its nutritional needs (Clarke 1997). Nepenthes is distributed in Northern Australia, South East Asia and Southern China, while vast majority occurred in Islands of Borneo and Sumatra. NR is one of the most common varieties of $\mathrm{Ne}$ penthes, found in open, sandy, wet areas, cleared areas, peat swamp forest and kerangas forest (heath forest) (Clarke 1997; Osunkoya et al. 2007). NR is characterised by its huge size and can be measured up to $35 \mathrm{~cm}$ long and $15 \mathrm{~cm}$ wide (Clarke 1997). NR also contains lignocellulosic materials (Osunkoya et al. 2008) which are known to adsorb dyes (Parab et al. 2010). Currently, there is no report of using Nepenthes as an adsorbent for remediation of dye wastewater. MV is a purple organic dye, belonging to the triphenylmethane class. MV is chosen as a dye of focus because of its industrial importance in textile, rubber, inkjet, paper and petroleum products (Sabnis 2010). MV is also a known irritant to eyes, skin, gastrointestinal and respiratory tract and is also a known carcinogenic and mutagenic agent (Michaels and Lewis 1985; Vachalkova et al. 1995). The novelty of this study is the use of pitcher plant as an adsorbent as no studies on the use of this plant as an adsorbent have previously been reported.

\section{Materials and methods}

\section{Preparation of adsorbent and dye stock solution}

Nepenthes pitcher (NP) and Nepenthes leaves (NL) were obtained from the hills outside the compound of Universiti Brunei Darussalam, Brunei Darussalam, Northern Borneo. Samples were washed with distilled water, sonicated and then dried in an oven at $70{ }^{\circ} \mathrm{C}$. Dried samples were blended into fine powder using a kitchen blender and then sieved size of $<355 \mu \mathrm{m}$ were collected and used for the adsorption experiment.

Methyl violet 2B dye (MV) ( $M_{\mathrm{r}} 393.95 \mathrm{~g} \mathrm{~mol}^{-1}, 80 \%$ dye content, Sigma-Aldrich) was used without further purification. A $500 \mathrm{mg} \mathrm{L}^{-1}$ stock solution was prepared and serial dilutions were carried out to obtain lower dye concentrations.

\section{Characterisations of adsorbents}

Fourier transform infrared (FTIR) spectra $(\mathrm{KBr}$ disc approach) were carried out using a Shimadzu Model IRPrestige-21 spectrophotometer. The surface morphology analyses of the adsorbents were carried out using a scanning electron microscope (SEM) (Tescan Vega XMU). The determination of the adsorbents' point of zero charge
$\left(\mathrm{pH}_{\mathrm{pzc}}\right)$ was done by salt addition approach using $0.1 \mathrm{~mol}$ $\mathrm{L}^{-1} \mathrm{KNO}_{3}$ solutions (Zehra et al. 2015). All measurements of $\mathrm{pH}$ were done using a Thermo-Scientific digital $\mathrm{pH}$ meter.

\section{Batch adsorption procedures}

In general, batch adsorption experiments were carried out by simply agitating $0.04 \mathrm{~g}$ of adsorbents in $20 \mathrm{~mL}$ dye solutions using an orbital shaker set at $250 \mathrm{rpm}$, unless stated otherwise.

Preliminary experiments were carried out to investigate the effect of adsorbent dosage, using $100 \mathrm{mg} \mathrm{L}^{-1} \mathrm{MV}$ (unadjusted $\mathrm{pH}$ ) with the studied adsorbent dosage ranged from 0.01 to $0.06 \mathrm{~g}$. The optimum adsorbent dosage was found to be $0.04 \mathrm{~g}$ for both NP and NL, and this was used throughout the experiment. The data is not shown for brevity.

The effects of $\mathrm{pH}(2-9)$, ionic strength $\left(0-0.8 \mathrm{~mol} \mathrm{~L}^{-1}\right)$, dye concentrations $\left(20-500 \mathrm{mg} \mathrm{L}^{-1}\right)$, and duration of agitation (0-180 min) were investigated. One parameter was changed at a time, while the rest were kept constant.

The adsorption capacity, $q_{\mathrm{e}}\left(\mathrm{mg} \mathrm{g}^{-1}\right)$, and removal efficiency (\%) were used for measuring the amount of dye adsorbed by the adsorbents. The equations are as followed:

$q_{\mathrm{e}}=\frac{\left(C_{\mathrm{i}}-C_{\mathrm{e}}\right) V}{m}$

Removal efficiency $=\frac{\left(C_{\mathrm{i}}-C_{\mathrm{e}}\right) \times 100 \%}{C_{\mathrm{i}}}$

where $C_{\mathrm{i}}$ is the initial dye concentration $\left(\mathrm{mg} \mathrm{L}^{-1}\right), C_{\mathrm{e}}$ is the dye concentration of the filtrate after adsorption $\left(\mathrm{mg} \mathrm{L}^{-1}\right)$, $V$ is dye volume (L) and $m$ is the adsorbent mass ( $\mathrm{g}$ ).

\section{Isotherm and kinetics modelling}

The adsorption data were fitted into six isotherm models, namely the Langmuir (1916), Freundlich (1906), DubininRadushkevich (D-R) (Dubinin and Radushkevich 1947), Tempkin (Tempkin and Pyzhev 1940), Redlich-Peterson (R-P) (Redlich and Peterson 1959) and Sips (1948) models, and also to various kinetics models such as the pseudofirst-order (PFO) (Lagergren 1898), pseudo-second-order (PSO) (Ho and McKay 1999) and Weber-Morris intraparticle diffusion (WMID) (Weber and Morris 1963) models. The equations and linear plots of these models are summarised in the Table 1.

\section{Error analyses}

The kinetics and isotherm models that best characterised the adsorption data are commonly chosen based on the values of 
Table 1 Equations of the isotherm and kinetics models

\begin{tabular}{|c|c|c|c|}
\hline Model & Linear equation & Plot & Equations \\
\hline \multicolumn{4}{|c|}{ Isotherm models } \\
\hline Langmuir & $\begin{array}{l}\frac{C_{\mathrm{e}}}{q_{\mathrm{e}}}=\frac{1}{k_{\mathrm{L}} q_{\mathrm{m}}}+\frac{C_{\mathrm{e}}}{q_{\mathrm{m}}} \\
R_{\mathrm{L}}=\frac{1}{\left(1+k_{\mathrm{L}} C_{\mathrm{o}}\right)}\end{array}$ & $\frac{C_{e}}{q_{e}}$ vs. $C_{\mathrm{e}}$ & (3) \\
\hline Freundlich & $\ln q_{\mathrm{e}}=\frac{1}{n_{\mathrm{F}}} \ln C_{\mathrm{e}}+\ln k_{\mathrm{F}}$ & $\ln q_{\mathrm{e}}$ vs. $\ln C_{\mathrm{e}}$ & (4) \\
\hline $\mathrm{D}-\mathrm{R}$ & $\begin{array}{l}\ln q_{\mathrm{e}}=\ln q_{\mathrm{m}}-k_{\mathrm{D}}^{2} \\
\varepsilon=R T \ln \left[1+\frac{1}{C_{\mathrm{e}}}\right] \\
E=\frac{1}{\sqrt{2 k_{D}}}\end{array}$ & $\ln q_{\mathrm{e}}$ vs $\varepsilon^{2}$ & (5) \\
\hline Tempkin & $q_{\mathrm{e}}=\frac{R T}{b} \ln k_{\mathrm{T}} C_{\mathrm{e}}$ & $q_{\mathrm{e}}$ vs. $\ln C_{\mathrm{e}}$ & (6) \\
\hline $\mathrm{R}-\mathrm{P}$ & $\ln \left(k_{\mathrm{R}} \frac{C_{\mathrm{e}}}{q_{\mathrm{e}}}-1\right)=\beta \ln C_{\mathrm{e}}+\ln a_{\mathrm{R}}$ & $\ln \left(k_{\mathrm{R}} \frac{C_{\mathrm{e}}}{q_{\mathrm{e}}}-1\right)$ vs. $\ln C_{\mathrm{e}}$ & (7) \\
\hline Sips & $\ln \left(\frac{q_{\mathrm{e}}}{q_{\mathrm{m}}-q_{\mathrm{e}}}\right)=k_{\mathrm{LF}} \ln C_{\mathrm{e}}+\ln k_{\mathrm{S}}$ & $\ln \left(\frac{q_{\mathrm{e}}}{q_{\mathrm{m}}-q_{\mathrm{e}}}\right)$ vs. $\ln C_{\mathrm{e}}$ & (8) \\
\hline \multicolumn{4}{|c|}{ Kinetics models } \\
\hline PFO & $\log \left(q_{\mathrm{e}}-q_{\mathrm{t}}\right)=\log q_{\mathrm{e}, \mathrm{cal}}-\frac{t}{2.303} k_{1}$ & $\left(\log q_{\mathrm{e}}-q_{\mathrm{t}}\right)$ vs. $t$ & (9) \\
\hline PSO & $\frac{t}{q_{\mathrm{t}}}=\frac{1}{q_{\mathrm{e}, \mathrm{cal}}^{2} k_{2}}+\frac{t}{q_{\mathrm{e}, \text { cal }}}$ & $\frac{t}{q_{\mathrm{t}}}$ vs. $t$ & $(10)$ \\
\hline WMID & $q_{\mathrm{t}}=k_{3} t^{1 / 2}+C$ & $q_{\mathrm{t}}$ vs. $t^{1 / 2}$ & $(11)$ \\
\hline
\end{tabular}

$q_{\mathrm{m}}$ is the maximum monolayer adsorption capacity $\left(\mathrm{mg} \mathrm{g}^{-1}\right), k_{\mathrm{L}}$ is the Langmuir adsorption constant $\left(\mathrm{L} \mathrm{mg}^{-1}\right), R_{\mathrm{L}}$ is the separation factor which indicates if the isotherm is unfavourable $\left(R_{\mathrm{L}}>1\right)$, linear $\left(R_{\mathrm{L}}=1\right)$, favourable $\left(0<R_{\mathrm{L}}<1\right)$, or irreversible $\left(R_{\mathrm{L}}=0\right), C_{\mathrm{o}}\left(\mathrm{mg} \mathrm{L}^{-1}\right)$ is the highest initial dye concentration, $k_{\mathrm{F}}\left(\mathrm{mg}^{1-1 / n} \mathrm{~L}^{1 / \mathrm{n}} \mathrm{g}^{-1}\right)$ is the adsorption capacity of the adsorbent, $n_{\mathrm{F}}$ (Freundlich constant) indicates the favourability of the adsorption process (favourable if value of $n_{\mathrm{F}}$ is between 1 and $10, k_{\mathrm{D}}$ is a $\mathrm{D}-\mathrm{R}$ constant $\left(\mathrm{mol}^{2} \mathrm{~kJ}^{-2}\right), \varepsilon$ is the Polanyi potential, $R$ is the gas constant $\left(8.314 \times 10^{-3} \mathrm{~kJ} \mathrm{~mol}^{-1} \mathrm{~K}^{-1}\right), T$ is temperature $(\mathrm{K}), E\left(\mathrm{~kJ} \mathrm{~mol}^{-1}\right)$ is the mean free energy, $b$ is the Tempkin isotherm constant $\left(\mathrm{kJ} \mathrm{mol}^{-1}\right), \mathrm{k}_{\mathrm{T}}$ is the equilibrium binding constant, $k_{\mathrm{R}}\left(\mathrm{L} \mathrm{g}^{-1}\right)$ and $a_{\mathrm{R}}\left(\mathrm{L} \mathrm{mg}^{-1}\right)$ are the R-P constants, $\beta$ is the R-P exponent, $k_{\mathrm{S}}\left(\mathrm{L} \mathrm{g}^{-1}\right)$ is the Sips constant, $k_{\mathrm{LF}}$ is the Sips exponent, $q_{\mathrm{t}}$ is the amount of dye adsorbed per gram of AP $\left(\mathrm{mg} \mathrm{g}^{-1}\right)$ at time $t$ (min), $k_{1}$ is the PFO rate constant $\left(\mathrm{min}^{-1}\right), k_{2}$ is PSO rate constant $\left(\mathrm{g} \mathrm{mg}^{-1} \mathrm{~min}^{-1}\right), k_{3}$ is the intraparticle diffusion rate constant $\left(\mathrm{mg} \mathrm{g}^{-1} \mathrm{~min}^{-1 / 2}\right)$ and $C$ is the intercept

the coefficient of determination $\left(R^{2}\right)$. However, the linearisation of kinetics and isotherm models from their non-linear forms may violate the normality assumptions of standard least squares, leading to error (Ho 2004; Ratkowsky 1990). Chi-square test $\left(\chi^{2}\right)$ and average relative error (ARE) are included in this study, to determine the best-fitted models. The equations of $\chi^{2}$ and ARE are as follow:

$\chi^{2}: \sum_{i=1}^{N} \frac{\left(q_{\mathrm{e}, \exp }-q_{\mathrm{e}, \mathrm{cal}}\right)^{2}}{q_{\mathrm{e}, \exp }}$

ARE $: \frac{100}{n} \sum_{i=1}^{N}\left|\frac{q_{\mathrm{e}, \exp }-q_{\mathrm{e}, \mathrm{cal}}}{q_{\mathrm{e}, \exp }}\right|_{i}$

where $q_{\mathrm{e}, \exp }$ is the $q_{\mathrm{e}}$ value obtained experimentally, $q_{\mathrm{e}, \mathrm{cal}}$ is the calculated value dived from the isotherm or kinetics models and $n$ is the number of data points included in the calculation.

\section{Thermodynamics experiments}

The thermodynamics nature of the adsorption process was investigated using the Van't Hoff equation (Eq. 14), and the studied temperature ranged from 25 to $65^{\circ} \mathrm{C}$. The equations are as follow:
$\Delta G^{\mathrm{O}}=H^{\mathrm{O}}-T \Delta S^{\mathrm{O}}=-R T \ln k$

$k=\frac{C_{\mathrm{i}}-C_{\mathrm{e}}}{C_{\mathrm{e}}}$.

$\ln k=\frac{\Delta S^{\mathrm{o}}}{R}-\frac{\Delta H^{\mathrm{o}}}{R T}$

where $T$ is the temperature $(\mathrm{K}), \Delta G^{\mathrm{o}}\left(\mathrm{kJ} \mathrm{mol}^{-1}\right)$ is the Gibbs' free energy, $\Delta S^{\mathrm{o}}\left(\mathrm{J} \mathrm{mol}^{-1} \mathrm{~K}^{-1}\right)$ is the entropy change, $\Delta H^{\mathrm{o}}\left(\mathrm{kJ} \mathrm{mol}^{-1}\right)$ is the enthalpy change, $k$ is the distribution coefficient for adsorption, and $R$ is the gas constant $\left(8.314 \mathrm{~J} \mathrm{~mol}^{-1} \mathrm{~K}^{-1}\right)$. The $\Delta S^{\mathrm{o}}$ and $\Delta H^{\mathrm{o}}$ were calculated from the linear plot of $\ln k$ vs $1 / T$.

\section{Regeneration experiment}

In this study, distilled water and $0.1 \mathrm{~mol} \mathrm{~L}^{-1} \mathrm{NaOH}$ were used for regenerating the spent adsorbents. The detailed procedure is available in our previous work (Dahri et al. 2014). Briefly, the spent adsorbents were washed in distilled water until no desorption occurs, and the regenerated adsorbents were dried in an oven at $70{ }^{\circ} \mathrm{C}$ overnight. To wash using $\mathrm{NaOH}$, the spent adsorbents were agitated for $30 \mathrm{~min}$, followed by repeated distilled water washing until 
the $\mathrm{pH}$ of the washed solution was near neutral and the regenerated adsorbents were then dried in an oven at $70{ }^{\circ} \mathrm{C}$.

\section{Results and discussion}

\section{Characterisation of adsorbents}

As summarised in Table 2, functional group analyses using FTIR revealed that both $\mathrm{NP}$ and $\mathrm{NL}$ contain $\mathrm{O}-\mathrm{H},-\mathrm{NH}_{3}$, aliphatic $\mathrm{C}-\mathrm{H}, \mathrm{N}-\mathrm{H}$, phenyl, $\mathrm{C}-\mathrm{O}-\mathrm{C}$, and $-\mathrm{COO}$ groups. For NP-MV and NL-MV, shifts of $\mathrm{O}-\mathrm{H},-\mathrm{NH}_{3}$ and -COO bands were observed which indicate that these groups may have interacted with the MV dye molecule.

\begin{tabular}{lllll}
\hline Functional group & \multicolumn{4}{l}{ Wavenumber $\left(\mathrm{cm}^{-1}\right)$} \\
\cline { 2 - 5 } & NP & NP-MV & NL & NL-MV \\
\hline O-H and $-\mathrm{NH}_{3}$ & 3384 & 3409 & 3378 & 3382 \\
Aliphatic C-H stretch & 2917 & 2919 & 2918 & 2918 \\
N-H bending & 1620 & 1620 & 1619 & 1620 \\
Phenyl & 1451 & 1451 & 1450 & 1450 \\
C-O-C & 1035 & 1036 & 1036 & 1036 \\
-COO anti-symmetric stretching & 1519 & 1519 & 1524 & 1514 \\
-COO symmetric stretching & 1377 & 1368 & 1370 & 1368 \\
\hline
\end{tabular}

The surface morphology of untreated and MV-treated adsorbents were as shown in Fig. 1. The surface of NP and $\mathrm{NL}$ appeared to be irregular in shape with some noticeable fibres. After dye treatment, there are no significant changes in the structure of both the adsorbents, therefore, did not result in any major distinguishable differences.

\section{Effects of pH and ionic strength}

The three main mechanisms for dye interaction with adsorbent are electrostatic interaction, hydrophobic-hydrophobic interaction and hydrogen bond. Electrostatic interaction is the attraction between the charged functional group of the adsorbent with the dye molecule of opposite charge. Hydrophobic-hydrophobic interaction occurs between the non-polar groups of dyes and the non-polar groups on an adsorbent's surface (Hu et al. 2013).

In adsorption study, $\mathrm{pH}$ and ionic strength are very important parameters to investigate. The $\mathrm{pH}$ can directly affect the functional groups on the adsorbents, as well as affecting the charge of the dye molecules, while the ionic strength can influence the electrostatic interaction between the dye and the adsorbent and the hydrophobic-hydrophobic interaction (Al-Degs et al. 2008; Hu et al. 2013).

The point of zero charge, $\mathrm{pH}_{\mathrm{pzc}}$, for NP and NL were determined to be 4.5 and 3.9, respectively. Theoretically,

Table 2 Summary of kinetics data fitted into PFO, PSO and WMID models

\begin{tabular}{|c|c|c|c|c|c|c|}
\hline & NP & & & NL & & \\
\hline \multicolumn{7}{|l|}{$\mathrm{PFO}$} \\
\hline$C_{\mathrm{i}}\left(\mathrm{mg} \mathrm{L}^{-1}\right)$ & 50 & 100 & 200 & 50 & 100 & 200 \\
\hline$q_{\mathrm{e}, \mathrm{cal}}\left(\mathrm{mg} \mathrm{g}^{-1}\right)$ & 4.9 & 2.1 & 12.2 & 5.3 & 6.9 & 36.4 \\
\hline$q_{\mathrm{e}, \exp }\left(\mathrm{mg} \mathrm{g}^{-1}\right)$ & 14.8 & 34.8 & 77.7 & 22.8 & 42.4 & 84.5 \\
\hline$k_{1}$ & 0.029 & 0.006 & 0.019 & 0.027 & 0.017 & 0.023 \\
\hline$R^{2}$ & 0.977 & 0.899 & 0.819 & 0.926 & 0.900 & 0.974 \\
\hline$\chi^{2}$ & 85 & 354 & 645 & 162 & 354 & 372 \\
\hline ARE & 65 & 83 & 77 & 72 & 77 & 60 \\
\hline \multicolumn{7}{|l|}{ PSO } \\
\hline$q_{\mathrm{e}, \mathrm{cal}}\left(\mathrm{mg} \mathrm{g}^{-1}\right)$ & 15.1 & 34.5 & 78.3 & 23.2 & 42.6 & 87.4 \\
\hline$q_{\mathrm{e}, \exp }\left(\mathrm{mg} \mathrm{g}^{-1}\right)$ & 14.8 & 34.8 & 77.7 & 22.8 & 42.4 & 84.5 \\
\hline$k_{2}$ & 0.0148 & 0.0258 & 0.0054 & 0.0134 & 0.0093 & 0.0015 \\
\hline$R^{2}$ & 0.999 & 1.000 & 1.000 & 1.000 & 1.000 & 0.999 \\
\hline$\chi^{2}$ & 3 & 1 & 10 & 3 & 3 & 28 \\
\hline ARE & 10 & 3 & 7 & 8 & 6 & 14 \\
\hline \multicolumn{7}{|c|}{ WMID (first linear region only) } \\
\hline$C_{\mathrm{i}}\left(\mathrm{mg} \mathrm{L}^{-1}\right)$ & 50 & 100 & 200 & 50 & 100 & 200 \\
\hline$k_{3}$ & 0.512 & 0.224 & 6.307 & 1.929 & 2.450 & 5.236 \\
\hline$C$ & 9.871 & 32.017 & 41.370 & 11.881 & 27.302 & 37.503 \\
\hline$R^{2}$ & 0.968 & 0.912 & 0.873 & 0.874 & 0.998 & 0.965 \\
\hline
\end{tabular}



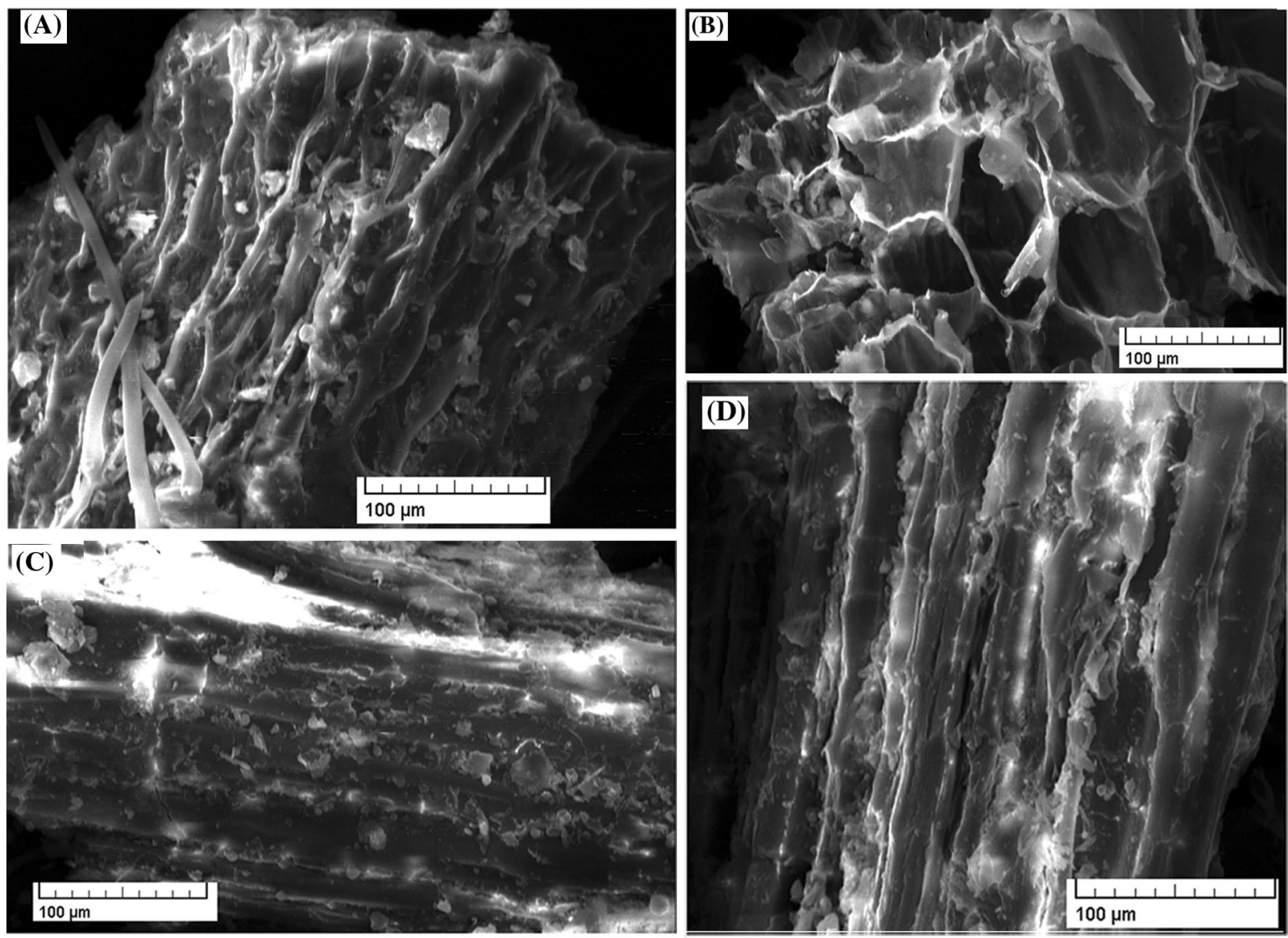

Fig. 1 SEM images of a NP, b NP-MV, $\mathbf{c}$ NL, and d NL-MV

the functional groups on the surface of NP will be predominate negatively charged at $\mathrm{pH}$ higher than 4.5 , and predominate positively charged at $\mathrm{pH}$ lower than 4.5. As seen in Fig. 2a, there was little influence of medium $\mathrm{pH}$ on adsorption of MV onto NP as the adsorbent. At $\mathrm{pH} 2.6$, the predominant positive charged surface of NP should lead to electrostatic repulsion with the cationic MV molecules, however, removal efficiency of $78 \%$ was obtained, which indicates that electrostatic interaction may not be the dominant mechanism for the interaction of NP-MV system. Similar observation was seen for the NL-MV system. Similar behaviour was also observed in our previous work on the removal of MV and malachite green dyes using Azolla pinnata (Kooh et al. 2015; Kooh et al. 2016c).

The effect of ionic strength is as shown in Fig. 2b, where the increase of ionic strength led to reduction of the removal efficiency. The removal efficiency decreased from 72 to $44 \%$ for NP, while NL decreased from 86 to $58 \%$, as $\mathrm{NaCl}$ concentration increased from 0 to $0.8 \mathrm{~mol}$ $\mathrm{L}^{-1}$. The reduction in removal efficiencies is due to the suppression of the electrostatic interaction as the surplus $\mathrm{Na}^{+}$ions compete with MV molecules for the adsorption sites (Hu et al. 2013). The increase of ionic strength also compressed the electrical double layer which moves the adsorbents and the dye molecules closer together which may enhance the hydrophobic-hydrophobic interactions (Binnie et al. 2002; Hu et al. 2013). Despite the suppression of electrostatic interaction, for the adsorption to maintain high removal efficiency at high ionic strength is an indication that hydrophobic-hydrophobic interaction may play larger role in NP-MV and NL-MV systems. Furthermore, the hydrophobic interaction can be enhanced by the presence of salt, whereby the electric double layer decreases in thickness allowing the dye molecules and adsorbent particles to move closer to each other (Binnie et al. 2002).

\section{Effect of contact time and kinetics modelling}

The effect of contact time is to ensure that the duration of agitation time is sufficient to attain the equilibrium of the adsorption process. As seen in Fig. 3a, b, the equilibrium for both NP-MV and NL-MV systems were achieved within $120 \mathrm{~min}$. The rapid increase in dye uptake during the first $60 \mathrm{~min}$ is due to the vacant adsorption sites, which become occupied and less available over time, resulting in

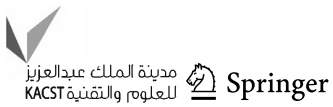




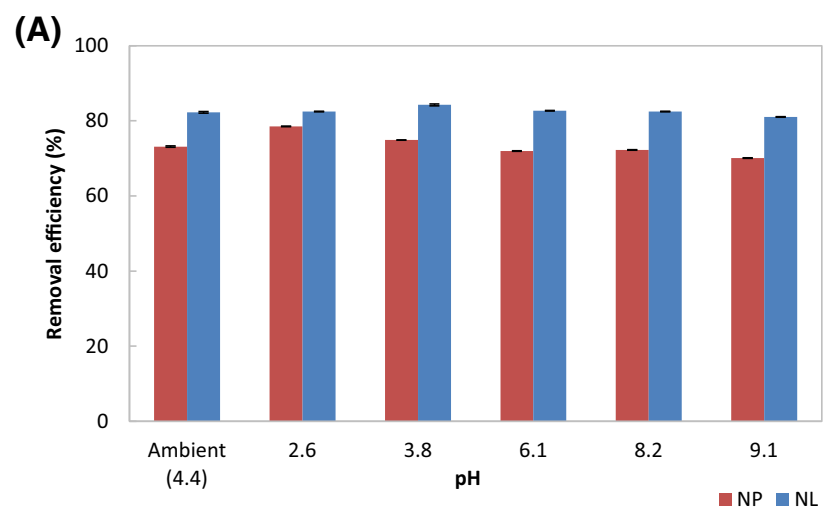

(B)

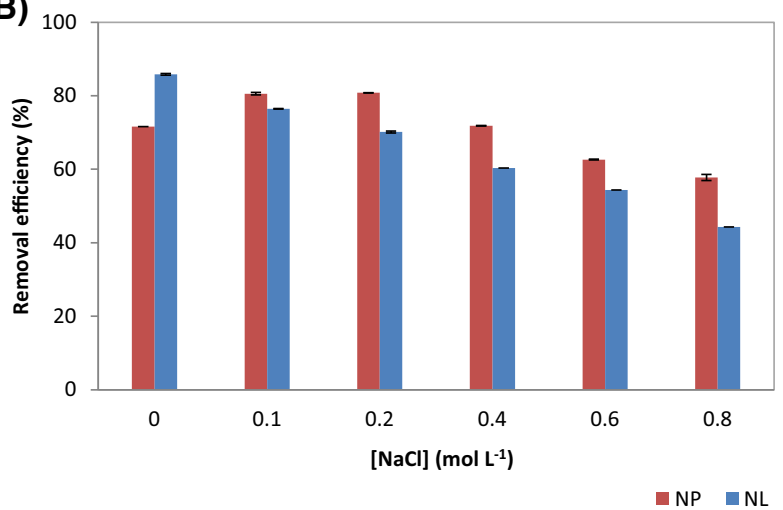

Fig. 2 Plots showing the effects of a pH $(0.04 \mathrm{~g}$ adsorbents, $20 \mathrm{~mL}$ $100 \mathrm{mg} \mathrm{L}^{-1}$ dye), and $\mathbf{b}$ ionic strength $(0.04 \mathrm{~g}$ adsorbents, $20 \mathrm{~mL}$ $100 \mathrm{mg} \mathrm{L}^{-1}$ dye, unadjusted $\mathrm{pH}$ )

the much lower increase in dye uptake and eventually reaching equilibrium.

The kinetics data were assessed using PFO and PSO kinetics models and the data are summarised in Table 2, where it can be observed that the $R^{2}$ for PSO is close to 1.0 when compared to PFO values. When comparing the $q_{\mathrm{e}, \mathrm{cal}}$ and $q_{\mathrm{e} \text { exp }}$, the values were also much closer for PSO, while for PFO the values are much further apart. Lastly, the $\chi^{2}$ and ARE values for PSO are very low compared to PFO. Therefore, based on $R^{2}$, comparison of $q_{\mathrm{e}, \mathrm{cal}}$ and $q_{\mathrm{e}, \mathrm{exp}}$, and the error functions values, the kinetics data for the removal of MV by both the adsorbents are best described by the PSO model. This indicates the rate of adsorption of NPMV, and NL-MV systems follows the second-order rate law, however, referring to the amount of adsorption sites on adsorbent's surface and not the amount of adsorbate in bulk solution (Liu 2008).

To describe the diffusion process, WMID is used as PFO, and PSO models were not applicable. The diffusion process can be generally divided into three phases: the rapid external diffusion phase, the intraparticle diffusion phase and the slow equilibrium phase. As seen in Fig. 3c, $\mathrm{d}$, multi-linearity of the WMID plots observed indicates the presence of different phases of adsorption (Wang and $\mathrm{Li}$
2007). The rapid external diffusion phase was not observed in the WMID plot and it is most likely to be completed within the first $5 \mathrm{~min}$ of agitation. The first linear region as seen in WMID plot is the intraparticle diffusion phase, while the second linear region is the slow equilibrium phase. The WMID model states that if the linear WMID plot crosses the origin, then the diffusion mechanism is controlled by intraparticle diffusion. As seen in Table 2, the intercepts, $C$, for both NP-MV and NL-MV adsorption systems are non-zero, therefore, indicating that the intraparticle diffusion is not the rate-limiting step. The $C$ is also proportional to the thickness of the boundary layer.

\section{Effect of initial dye concentrations and isotherm modeling}

The effect of initial dye concentrations is as shown in Fig. 4, where it can be observed that increase of dye concentration resulted in higher dye adsorption. This behaviour is attributed to the Fick's diffusion law which stated that the concentration gradient provides driving force for the mass transfer rate, hence higher $C_{\mathrm{i}}$ resulted in higher $q_{\mathrm{e}}$ (Frijlink et al. 2015).

The experimental data on the adsorption of MV onto NP and NL were fitted to five different isotherm models. These isotherm models are useful to describe the adsorption process and each of the isotherm models' applications and theories are discussed in literature (Foo and Hameed 2010). Table 3 summarises the parameters for the isotherm models, as well as the error analyses. Comparing the five isotherm models' $R^{2}$ values for NP, it can be seen that Langmuir $>$ Freundlich $>$ Sips $>$ Tempkin $>$ R-P $>$ D-

$\mathrm{R}$ while for NL, Langmuir $>$ Sips $>$ Tempkin $>$ Freundlich $>$ D-R $>$ R-P. This indicates that the Langmuir is the best fit isotherm model for the experimental data of both the adsorbents which is further supported by the low $\chi^{2}$ and ARE values. Thus, according to the Langmuir model, the monolayer adsorption is involved.

The Freundlich model has poor fitting into the experimental data as it is more suitable to be used on low concentration of dye (Foo and Hameed 2010; Rushton et al. 2005). D-R model was originally used to describe adsorption of gas onto activated carbon with van der Waals forces as the main mechanism. In this study, the adsorption process involved many mechanisms, which is why the $\mathrm{D}-\mathrm{R}$ model displayed poor fitting into the data. Tempkin model excels in gas phase equilibrium prediction but is not suitable to be used in complex adsorption system (Kim et al. 2004).

The $R_{\mathrm{L}}$ values for NP and NL are both determined as 0.1 which suggested that the adsorption process is favourable. The $q_{\mathrm{m}}$ value for $\mathrm{NP}$ is $288 \mathrm{mg} \mathrm{g}^{-1}$ while for NL is $194 \mathrm{mg} \mathrm{g}^{-1}$. Both adsorbents' MV removing capacities are 
(A)

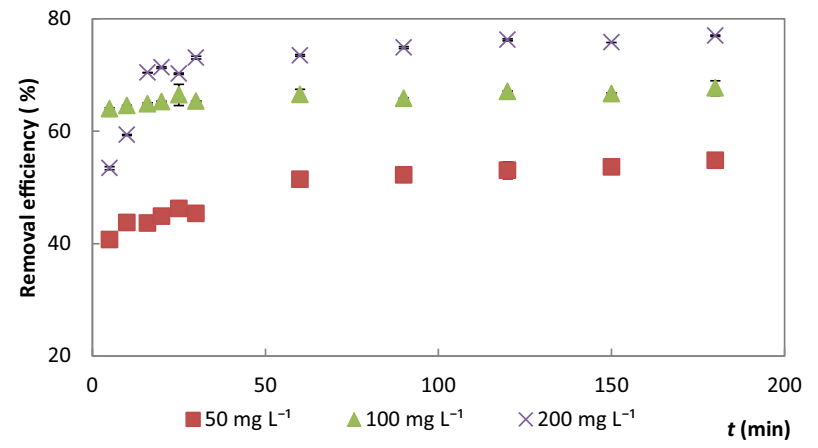

(C)

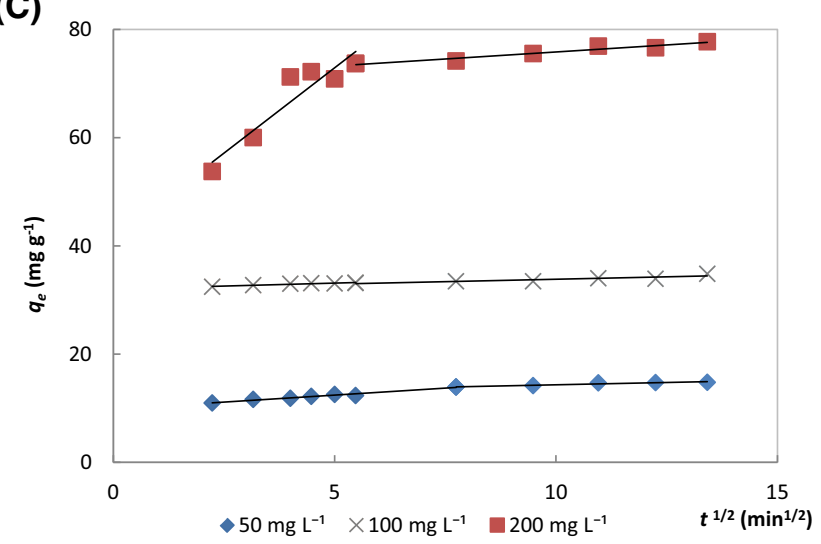

(B)

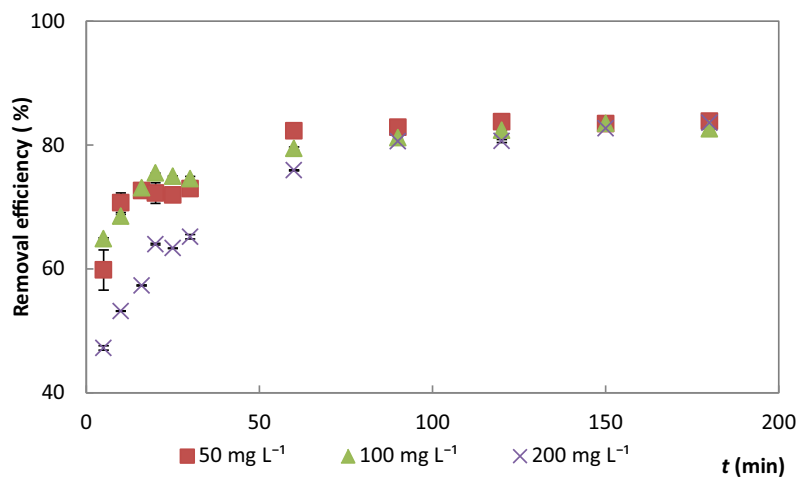

(D)

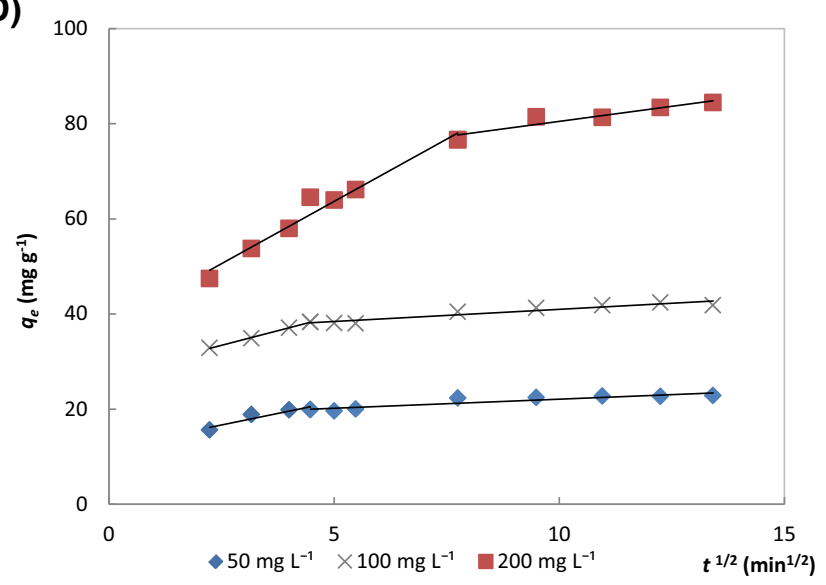

Fig. 3 Plots showing the effect of contact time for a NP-MV, b NL-MV, using three different concentrations of MV, and the WMID plot of c NP-MV and d NL-MV

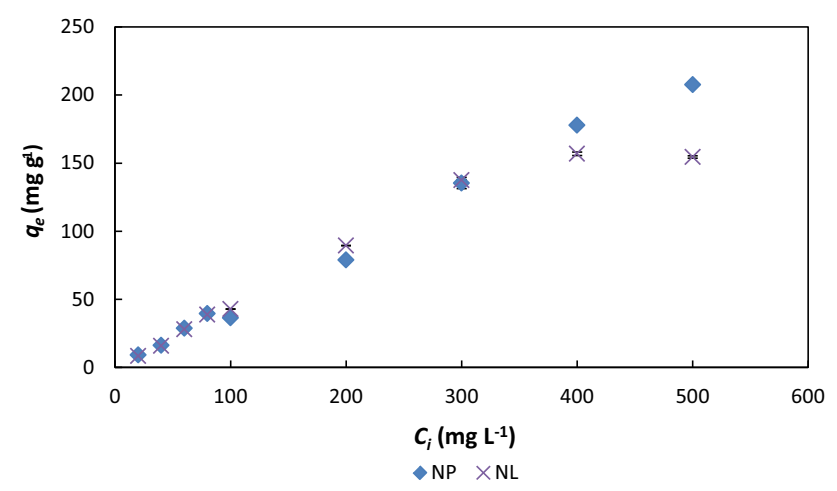

Fig. 4 Plots showing the effect of initial dye concentration for NPMV and NL-MV systems

better than peanut straw char $\left(101 \mathrm{mg} \mathrm{g}^{-1}\right)$ (Xu et al. 2011), Posidonia oceanic leaf (119 $\mathrm{mg} \mathrm{g}^{-1}$ ) (Cengiz and Cavas 2010), jackfruit seed (126.7 $\mathrm{mg} \mathrm{g}^{-1}$ ) (Dahri et al. 2016) and Casuarina equisetifolia needle (165.0 $\mathrm{mg} \mathrm{g}^{-1}$ ) (Dahri et al. 2013). NP ability to remove MV is on par with pu-erh tea (286 $\mathrm{mg} \mathrm{g}^{-1}$ ) (Li et al. 2010) while NL is on par with soyabean waste $\left(180 \mathrm{mg} \mathrm{g}^{-1}\right)$ (Kooh et al. 2016b) and
Azolla pinnata (194 $\mathrm{mg} \mathrm{g}^{-1}$ ) (Kooh et al. 2015), however, lower than water lettuce (267.6 $\mathrm{mg} \mathrm{g}^{-1}$ ) (Lim et al. 2016) and duckweed (332.5 $\mathrm{mg} \mathrm{g}^{-1}$ ) (Lim et al. 2014).

\section{Thermodynamics experiment}

Thermodynamics experiments provide useful insights on the thermodynamics nature of the adsorption process. The $\Delta G^{\mathrm{o}}$ obtained for the NP-MV system at the temperature 25, $35,45,55$ and $65^{\circ} \mathrm{C}$ are $-2.27,-2.55,-2.42,-2.86$ and $-3.24 \mathrm{~kJ} \mathrm{~mol}^{-1}$, respectively, while for the NL-MV system are $-3.58,-4.55,-5.19,-4.77$ and $-5.33 \mathrm{~kJ} \mathrm{~mol}^{-1}$. The negative $\Delta G^{\mathrm{o}}$ values indicates that the adsorption process for both NP-MV and NL-MV systems are spontaneous. The $\Delta H^{\mathrm{o}}$ for NP-MV and NL-MV systems are 3.91 and $7.40 \mathrm{~kJ} \mathrm{~mol}^{-1}$, respectively, which indicate that the adsorption processes for both the adsorbents is endothermic in nature. The $\Delta S^{\mathrm{o}}$ for NP-MV and NL-MV systems are 20.5 and $37.7 \mathrm{~J} \mathrm{~mol}^{-1} \mathrm{~K}^{-1}$, respectively, where the positive values indicate favourable and increase of randomness in the adsorption. 
Table 3 Summary of parameters of six isotherm models

\begin{tabular}{|c|c|c|}
\hline Absorbent & NP & NL \\
\hline \multicolumn{3}{|l|}{ Langmuir } \\
\hline$q_{\mathrm{m}}\left(\mathrm{mg} \mathrm{g}^{-1}\right)$ & 288.7 & 194.0 \\
\hline$k_{\mathrm{L}}$ & 0.017 & 0.022 \\
\hline$R_{\mathrm{L}}$ & 0.1 & 0.1 \\
\hline$R^{2}$ & 0.936 & 0.955 \\
\hline$\chi^{2}$ & 24.9 & 16.4 \\
\hline ARE & 22.8 & 19.1 \\
\hline \multicolumn{3}{|l|}{ Tempkin } \\
\hline$b\left(\mathrm{~kJ} \mathrm{~mol}^{-1}\right)$ & 57.5 & 61.7 \\
\hline$k_{\mathrm{T}}\left(\mathrm{L} \mathrm{g}^{-1}\right)$ & 0.346 & 0.307 \\
\hline$R^{2}$ & 0.789 & 0.945 \\
\hline$\chi^{2}$ & 187.4 & 17.9 \\
\hline ARE & 57.2 & 19.3 \\
\hline \multicolumn{3}{|l|}{ Dubinin-Radushkevich } \\
\hline$q_{\mathrm{m}}\left(\mathrm{mg} \mathrm{g}^{-1}\right)$ & 88.4 & 99.5 \\
\hline$k_{\mathrm{D}}\left(\mathrm{mol}^{2} \mathrm{~kJ}^{-2}\right)$ & 3.4 & 7.4 \\
\hline$E\left(\mathrm{~kJ} \mathrm{~mol}^{-1}\right)$ & 0.386 & 0.259 \\
\hline$R^{2}$ & 0.659 & 0.845 \\
\hline$\chi^{2}$ & 228.1 & 110 \\
\hline ARE & 57.7 & 40.6 \\
\hline \multicolumn{3}{|l|}{ Freundlich } \\
\hline$k_{\mathrm{F}}\left(\mathrm{mg}^{1-1 / \mathrm{n}} \mathrm{L}^{1 / \mathrm{n}} \mathrm{g}^{-1}\right)$ & 2.732 & 1.922 \\
\hline$n_{\mathrm{F}}$ & 1.095 & 1.028 \\
\hline$R^{2}$ & 0.893 & 0.885 \\
\hline$\chi^{2}$ & 63.2 & 441.8 \\
\hline ARE & 36.7 & 52.4 \\
\hline \multicolumn{3}{|l|}{ Redlich-Peterson } \\
\hline$k_{\mathrm{R}}\left(\mathrm{L} \mathrm{g}^{-1}\right)$ & 11 & 6.7 \\
\hline$a_{\mathrm{R}}\left(\mathrm{L} \mathrm{mg}^{-1}\right)$ & 0.7 & 0.4 \\
\hline$\beta$ & 0.409 & 0.49 \\
\hline$R^{2}$ & 0.682 & 0.609 \\
\hline$\chi^{2}$ & 103 & 84.8 \\
\hline ARE & 36.6 & 27.1 \\
\hline \multicolumn{3}{|l|}{ Sips } \\
\hline$q_{\mathrm{m}}\left(\mathrm{mg} \mathrm{g}^{-1}\right)$ & 215 & 161 \\
\hline$k_{\mathrm{s}}\left(\mathrm{L} \mathrm{mg}^{-1}\right)$ & 0.015 & 0.009 \\
\hline$k_{\mathrm{LF}}$ & 0.74 & 0.643 \\
\hline$R^{2}$ & 0.818 & 0.951 \\
\hline$\chi^{2}$ & 166.4 & 16.4 \\
\hline ARE & 39.2 & 23.2 \\
\hline
\end{tabular}

\section{Regeneration experiment}

Disposal of spent adsorbent by conventional methods may not be ideal, i.e., sending to the landfill will cause the hazardous wastes to leach from the spent adsorbent, while incineration may lead to release of poisonous gases.
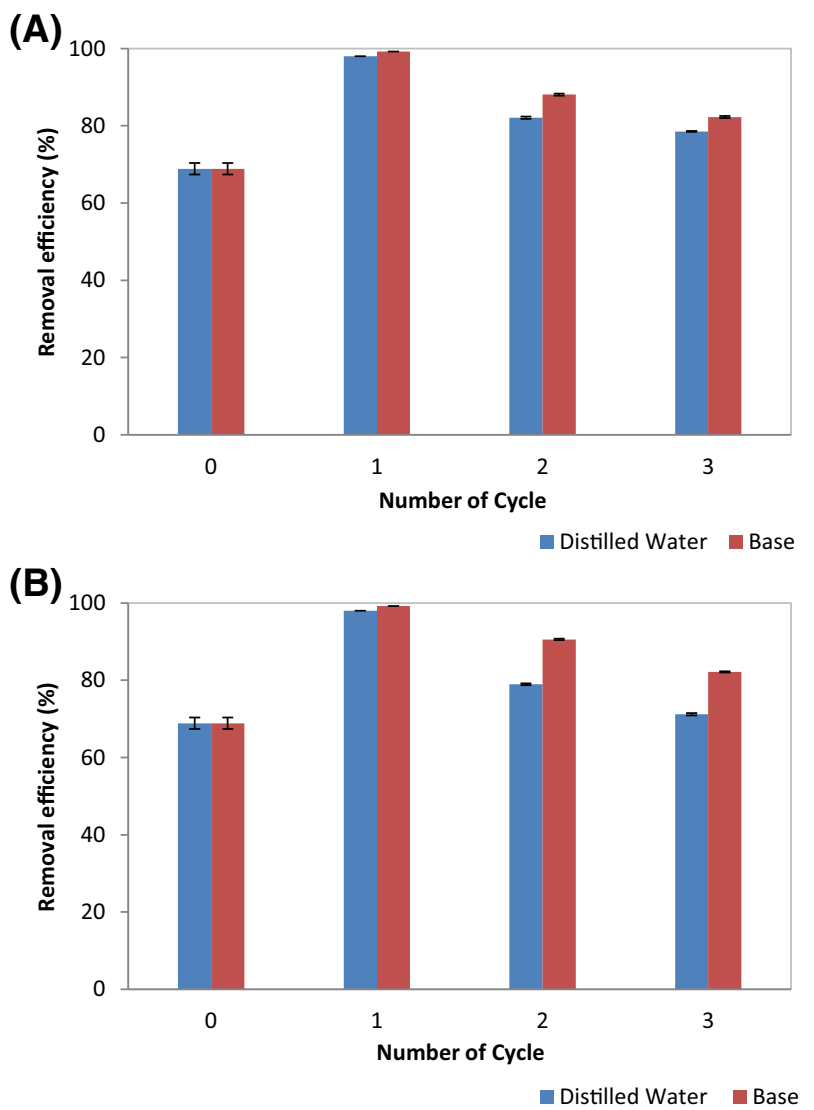

Fig. 5 Regeneration experiments showing several wash cycles using distilled water and $\mathrm{NaOH}$ for $\mathbf{a} \mathrm{NP}$ and $\mathbf{b} \mathrm{NL}$

Alternative method such as the use of regenerated spent adsorbent is not only esthetic, but also provided added value to the adsorbent in respect to its reusability. The data of regeneration experiment is as shown in Fig. 5. Washing using distilled water and the base were able to regenerate the spent adsorbents and achieved removal efficiencies higher than unused adsorbent. Regeneration using base was able to achieve removal efficiency higher than distilled water washing. This behaviour is not uncommon and could be due to removal of lignin and low molecular weight wax caused by repeated washing, leading to the exposure of adsorption sites favourable for adsorption of MV dyes and has also been observed in our previous work (Kooh et al. 2016c).

\section{Conclusions}

In this study, we report the use of two new adsorbents derived from Nepenthes rafflesia for the removal of toxic methyl violet 2B dye. Both the adsorbents gave high maximum adsorption capacities towards MV dye as compared to many reported natural adsorbents. Kinetics of the 
adsorption process followed the pseudo-second-order and intraparticle diffusion was found not to be the rate determining step. Both the adsorbents were also able to maintain its removal efficiency under different medium $\mathrm{pH}$. High $q_{\mathrm{m}}$ values coupled with successful regeneration of the spent adsorbents gave added values for them to be utilized as potential adsorbents for the removal of MV dye in wastewater treatment.

Acknowledgements Appreciation is given to the Government of Brunei Darussalam and Universiti Brunei Darussalam (UBD) for their offer of Graduate Research Studies scholarship. Appreciation also goes to the Applied Physics and the Environment and Life Sciences Sections of UBD for the usage of the SEM instrument.

\section{Compliance with ethical standards}

Funding There are no direct funding to this research study.

Conflict of interest All authors declared no conflict of interest.

Open Access This article is distributed under the terms of the Creative Commons Attribution 4.0 International License (http:// creativecommons.org/licenses/by/4.0/), which permits unrestricted use, distribution, and reproduction in any medium, provided you give appropriate credit to the original author(s) and the source, provide a link to the Creative Commons license, and indicate if changes were made.

\section{References}

Agarwal S, Tyagi I, Gupta VK, Dehghani M, Jaafari J, Balarak D, Asif M (2016) Rapid removal of noxious nickel (II) using novel $\gamma$-alumina nanoparticles and multiwalled carbon nanotubes: Kinetic and isotherm studies. J Mol Liq 224:618-623

Al-Degs YS, El-Barghouthi MI, El-Sheikh AH, Walker GM (2008) Effect of solution $\mathrm{pH}$, ionic strength, and temperature on adsorption behavior of reactive dyes on activated carbon. Dyes Pigment 77:16-23

Binnie C, Kimber M, Smethurst G (2002) Basic water treatment, 3rd edn. Royal Society of Chemistry, Cambridge

Cengiz S, Cavas L (2010) A promising evaluation method for dead leaves of Posidonia oceanica (L.) in the adsorption of methyl violet. Mar Biotechnol 12:728-736

Clarke C (1997) Nepenthes of Borneo. Natural History Publications Kota Kinabalu, Sabah

Dahri MK, Kooh MRR, Lim LBL (2013) Removal of methyl violet 2B from aqueous solution using Casuarina equisetifolia needle. ISRN Environ Chem 2013:1-8. doi:10.1155/2013/619819

Dahri MK, Kooh MRR, Lim LBL (2014) Water remediation using low cost adsorbent walnut shell for removal of malachite green: equilibrium, kinetics, thermodynamic and regeneration studies. J Environ Chem Eng 2:1434-1444. doi:10.1016/j.jece.2014.07. 008

Dahri MK, Kooh MRR, Lim LBL (2016) Adsorption of toxic methyl violet $2 \mathrm{~B}$ dye from aqueous solution using Artocarpus heterophyllus (Jackfruit) seed as an adsorbent. Am Chem Sci J 15:1-12

de Lima ROA, Bazo AP, Salvadori DMF, Rech CM, de Palma Oliveira D, de Aragão Umbuzeiro G (2007) Mutagenic and carcinogenic potential of a textile azo dye processing plant effluent that impacts a drinking water source. Mutat Res/Genet Toxicol Environ Mutagen 626:53-60
Dubinin MM, Radushkevich LV (1947) Equation of the characteristic curve of activated charcoal. P Acad Sci Phy Chem Sect 55:331

Foo KY, Hameed BH (2010) Insights into the modeling of adsorption isotherm systems. Chem Eng J 156:2-10. doi:10.1016/j.cej.2009. 09.013

Freundlich HMF (1906) Over the adsorption in solution. J Phys Chem $57: 385-470$

Frijlink E, Touw D, Woerdenbag H (2015) Biopharmaceutics. In: Bouwman-Boer Y, Fenton-May VI, Le Brun P (eds) Practical pharmaceutics: an international guideline for the preparation, care and use of medicinal products. Springer International Publishing, Cham, pp 323-346

Gupta VK, Nayak A (2012) Cadmium removal and recovery from aqueous solutions by novel adsorbents prepared from orange peel and $\mathrm{Fe}_{2} \mathrm{O}_{3}$ nanoparticles. Chem Eng J 180:81-90. doi:10. 1016/j.cej.2011.11.006

Ho Y-S (2004) Selection of optimum sorption isotherm. Carbon 42:2115-2116

Ho YS, McKay G (1999) Pseudo-second order model for sorption processes. Process Biochem 34:451-465

Hu Y, Guo T, Ye X, Li Q, Guo M, Liu H, Wu Z (2013) Dye adsorption by resins: effect of ionic strength on hydrophobic and electrostatic interactions. Chem Eng J 228:392-397. doi:10. 1016/j.cej.2013.04.116

Kant R (2012) Textile dyeing industry an environmental hazard. Natl Sci 4:22-26

Kim Y, Kim C, Choi I, Rengaraj S, Yi J (2004) Arsenic removal using mesoporous alumina prepared via a templating method. Environ Sci Technol 38:924-931

Kooh MRR, Lim LBL, Dahri MK, Lim LH, Sarath Bandara JMR (2015) Azolla pinnata: an efficient low cost material for removal of methyl violet $2 \mathrm{~B}$ by using adsorption method. Waste Biomass Valoriz 6:547-559. doi:10.1007/s12649-015-9369-0

Kooh MR, Lim LB, Lim LH, Dhari MK (2016a) Phytoremediation capability of Azolla pinnata for the removal of malachite green from aqueous solution. J Environ Biotechnol Res 5:10-17

Kooh MRR, Dahri MK, Lim LBL, Lim LH, Malik OA (2016b) Batch adsorption studies of the removal of methyl violet $2 \mathrm{~B}$ by soya bean waste: isotherm, kinetics and artificial neural network modelling. Environ Earth Sci 75:1-14. doi:10.1007/s12665-016-5582-9

Kooh MRR, Lim LBL, Lim LH, Bandara JMRS (2016c) Batch adsorption studies on the removal of malachite green from water by chemically modified Azolla pinnata. Desalin Water Treat 57:14632-14646. doi:10.1080/19443994.2015.1065450

Lagergren S (1898) Zur Theorie der Sogenannten Adsorption gel Ster Stoffe. K Sven Vetensk akad Handl 24:1-39

Langmuir I (1916) The constitution and fundamental properties of solids and liquids. J Am Chem Soc 38:2221-2295

Li P, Su YJ, Wang Y, Liu B, Sun LM (2010) Bioadsorption of methyl violet from aqueous solution onto Pu-erh tea powder. J Hazard Mat 179:43-48

Lim LBL, Priyantha N, Chan CM, Matassan D, Chieng HI, Kooh MRR (2014) Adsorption behavior of methyl violet 2B using duckweed: equilibrium and kinetics studies. Arab J Sci Eng 39:6757-6765. doi:10.1007/s13369-014-1224-2

Lim LBL, Priyantha N, Chan CM, Matassan D, Chieng HI, Kooh MRR (2016) Investigation of the sorption characteristics of water lettuce (WL) as a potential low-cost biosorbent for the removal of methyl violet 2B. Desalin Water Treat 57:8319-8329. doi:10.1080/19443994.2015.1017740

Liu Y (2008) New insights into pseudo-second-order kinetic equation for adsorption. Colloids Surf A Physicochem Eng Aspects 320:275-278. doi:10.1016/j.colsurfa.2008.01.032

Michaels GB, Lewis DL (1985) Sorption and toxicity of azo and triphenylmethane dyes to aquatic microbial populations. Environ Toxicol Chem 4:45-50

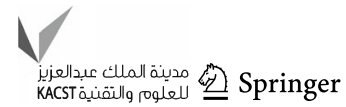


Osunkoya OO, Daud SD, Di-Giusto B, Wimmer FL, Holige TM (2007) Construction costs and physico-chemical properties of the assimilatory organs of Nepenthes species in northern Borneo. Ann Bot 99:895-906

Osunkoya OO, Daud SD, Wimmer FL (2008) Longevity, lignin content and construction cost of the assimilatory organs of nepenthes species. Ann Bot 102:845-853. doi:10.1093/aob/mcn162

Parab H, Joshi S, Sudersanan M, Shenoy N, Lali A, Sarma U (2010) Removal and recovery of cobalt from aqueous solutions by adsorption using low cost lignocellulosic biomass-coir pith. J Environ Sci Health Part A 45:603-611

Rasul MG, Faisal I, Khan MMK (2006) Environmental pollution generated from process industries in Bangladesh. Int $\mathbf{J}$ Environ Pollut 28:144-161

Ratkowsky DA (1990) Handbook of nonlinear regression models. Marcel Dekker Inc, New York

Redlich O, Peterson DL (1959) A useful adsorption isotherm. J Phys Chem 63:1024

Rushton GT, Karns CL, Shimizu KD (2005) A critical examination of the use of the Freundlich isotherm in characterizing molecularly imprinted polymers (MIPs). Anal Chim Acta 528:107-113

Sabnis RW (2010) Handbook of biological dyes and stains: synthesis and industrial applications. Wiley, Hoboken

Saravanan R, Thirumal E, Gupta VK, Narayanan V, Stephen A (2013) The photocatalytic activity of $\mathrm{ZnO}$ prepared by simple thermal decomposition method at various temperatures. J Mol Liq 177:394-401. doi:10.1016/j.molliq.2012.10.018

Sips R (1948) Combined form of Langmuir and Freundlich equations. J Chem Phys 16:490-495

Tempkin MI, Pyzhev V (1940) Kinetics of ammonia synthesis on promoted iron catalyst. Acta Physiochim USSR 12:327-356

Vachalkova A, Novotný L, Blesova M (1995) Polarographic reduction of some triphenylmethane dyes and their potential carcinogenic activity. Neoplasma 43:113-117

Wang S, Li H (2007) Kinetic modelling and mechanism of dye adsorption on unburned carbon. Dyes Pigments 72:308-314

Wang M-H, Li J, Ho Y-S (2011) Research articles published in water resources journals: a bibliometric analysis. Desalin Water Treat 28:353-365

Weber W, Morris J (1963) Kinetics of adsorption on carbon from solution. J Sanit Eng Div 89:31-60

Xu R, Xiao S, Yuan J, Zhao A (2011) Adsorption of methyl violet from aqueous solutions by the biochars derived from crop residues. Bioresour Technol 102:10293-10298

Zehra T, Priyantha N, Lim LBL, Iqbal E (2015) Sorption characteristics of peat of Brunei Darussalam V: removal of Congo red dye from aqueous solution by peat. Desalin Water Treat 54:2592-2600. doi:10.1080/19443994.2014.899929 